Ensaios

Bettina Fritzsche

Freie Universität Berlin

\title{
Negociando o feminismo pop na cultura jovem feminina: um estudo empírico com fãs de grupos femininos
}

\begin{abstract}
Resumo: As Spice Girls são um dos mais bem-sucedidos grupos musicais da década de 1990, tendo se tornado especialmente famosas por sua exaltação do 'poder jovem feminino'. Relacionado a um estudo que se baseia em entrevistas com fãs e ex-fãs desse grupo feminino, o presente artigo discute até que ponto fenômenos do 'feminismo pop' como as Spice Girls podem ser considerados uma fonte de empoderamento para meninas e jovens. O método documentário é utilizado por permitir a análise da recepção midiática como parte de uma cultura popular. Uma abordagem mimética em relação às Spice Girls no interior dessa cultura popular possibilita que suas fãs ocupem identificações diferenciadas na busca de seu próprio posicionamento diante das exigências contraditórias que a sociedade faz às adolescentes. Demonstra-se que suas complicadas negociações se referem a um empoderamento que não pode ser adequadamente categorizado como resistência ou incorporação ideológica.

Palavras-chave: cultura jovem feminina, feminismo, mímese, metodologia em estudos de público.
\end{abstract}

Copyright (c) 2004 by Revista Estudos Feministas

${ }^{1}$ GROSSBERG, 1995, p. 373.
O fenomenal sucesso globalizado das Spice Girls vem sendo acompanhado, desde seu início, tanto por reações negativas quanto por positivas. Isso acontece não só entre seu público predominantemente pré-adolescente, mas também com críticos e estudiosos adultos. A história desse grupo feminino é um excelente exemplo do estrelato moderno, conforme caracterizado por Lawrence Grossberg:' as Spice Girls são um grupo musical organizado conforme estratégias de mercado. As jovens são celebridades sem história, catapultadas para um estrelato que parecia já estar lá, esperando por elas. Conseqüentemente, o público foi levado a descobrir seus talentos apenas após elas terem se tornado estrelas. 
${ }^{2}$ Marjorie GARBER, 1993, p. 127.

${ }^{3}$ ROLLING STONE, 1997, p. 83.

${ }^{4}$ WALD, 1998, p. 588.

${ }^{5}$ MCROBBIE, 1998.

- Para análises detalhadas de como as Spice Girls se representam em suas letras, músicas, vídeos e outros textos populares, ver também Nicola DIBBEN, 1999; e Dafna LEMISH, 2003.

7 Ver, por exemplo, Janice RADWAY, 1988; Ien ANG, 1990 e 1996; e Nicholas ABERCROMBIE e Brian LONGHURST, 1998.
Um desses 'talentos', a proclamação e incorporação do 'poder feminino', gerou muita controvérsia. Por várias razões, a noção de um poder feminino tem sido especialmente criticado a partir de uma perspectiva feminista. As Spice Girls foram acusadas de não apresentar nada mais do que uma versão tépida e comercializada de um estilo já introduzido por predecessoras como Madonna e as Riot Grrrls. Enquanto que as Riot Grrrls foram um movimento de explícita subcultura, com intenções explicitamente feministas e manifestações agressivas da sexualidade feminina, Madonna fascinou acadêmicos com seu jogo parodístico dos atributos de gênero, um jogo que podia ser celebrado como "o poder do travesti". ${ }^{2} \mathrm{Em}$ comparação, a versão de poder feminino das Spice Girls parece ser, nas palavras da Rolling Stone, 3 "uma cooptação mais abominável do que o pior pesadelo de qualquer uma das riot grrrls". Uma outra crítica, formulada por Gayle Wald, ${ }^{4}$ advertia que uma celebração indiscriminada da juventude feminina poderia reforçar a noção patriarcal de que as mulheres seriam aceitas socialmente desde que se dispusessem a um comportamento infantil. Mas as Spice Girls também tiveram seus defensores. Angela McRobbie ${ }^{5}$ as considera um sintoma do feminismo popular, lutando de forma lúdica pela auto-afirmação e pelo prazer sexual, dissociando-se de uma antiga geração de feministas cansadas, brancas e de classe média. ${ }^{6}$

Apesar dessa controvérsia, o grupo de jovens tornouse, especialmente em seu bem-sucedido início de carreira, o objeto da admiração de muitas jovens entusiastas. Neste trabalho, estarei discutindo, com base em dados obtidos através de entrevistas, até que ponto os fenômenos 'feministas pop' como as Spice Girls podem ser considerados uma fonte de empoderamento para garotas e jovens. O interesse por essa questão vem acompanhado por um problema metodológico, já que o modo pelo qual as fãs 'consomem' o grupo obviamente difere das leituras cognitivas das acadêmicas acima mencionadas. Como especialistas em Estudos Culturais já apontaram, o consumo da mídia hoje em dia não pode ser visto como um processo isolado de codificação, mas deve ser examinado como um fenômeno que faz parte do cotidiano. ${ }^{7}$ A utilização de fãs pela mídia, exemplificada por práticas como a coleção de posters, não é apenas um ato de interpretação mas uma parte integral da cultura popular. Por essa razão, minha análise terá como foco o significado que as fãs das Spice Girls atribuem ao grupo dentro de sua cultura particular.

Nesse sentido, as entrevistas que realizei não focalizaram as reflexões das garotas sobre o grupo e sim suas ações na condição de fãs. No início das entrevistas 
8 Para mais detalhes sobre 0 método documentário, ver MANNHEIM, 1952; e Ralf BOHNSACK, Peter LOOS e Aglaja PRZYBORSKI, 2001.

${ }^{9}$ As entrevistas fazem parte de um estudo empírico mais amplo sobre fãs de grupos masculinos e de grupos femininos.

${ }^{10}$ GEBAUER e WULF, 1998, p. 11. narrativas, a partir da pergunta "Como você se tornou uma fã e o que aconteceu desde então?", as entrevistadas tiveram a oportunidade de narrar suas biografias como fãs. O método documentário, seguindo a tradição da Escola de Chicago e da "sociologia do conhecimento", conforme conceitualizada por Karl Mannheim, ${ }^{8}$ foi escolhido como o método de interpretação. O método documentário concentra-se nas narrações e descrições do texto da entrevista que fornecem informações sobre as ações das/ os entrevistadas/os e sobre a constituição da experiência que embasa tais ações. O objetivo não é descobrir, sob as narrativas das entrevistadas, um nível latente que permanece desconhecido para elas e inacessível à entrevistadora, e sim reconstruir experiências que muitas vezes não são formuladas diretamente. As experiências, no entanto, são muitas vezes documentadas na entrevista, permitindo que se formulem conclusões sobre os principais padrões de orientação. Dessa forma, o método documentário permite analisar a cultura das fãs no contexto de suas experiências e orientações enquanto adolescentes. Meu corpus consiste de oito entrevistas narrativas e uma discussão em grupo com fãs e ex-fãs das Spice Girls, com idade entre 10 e 17 anos. As entrevistadas são de vários níveis sociais e residem em diferentes localidades rurais e urbanas da Alemanha. ${ }^{9}$

Alguns dos aspectos típicos da cultura de fã-clube que permitem com que fãs participem de trocas dentro do grupo incluem coleções de CDs e outros itens, e um conhecimento profundo do assunto. Às vezes essas práticas constituem verdadeiros rituais de amizade entre as meninas (por exemplo, um telefonema diário para a melhor amiga pode se tornar um modo de trocar informações sobre o grupo). Na cultura de fã-clube de grupos femininos, a "imitação" também desempenha um papel importante. Ela se manifesta na criação de uma "minitribo de Spice Girls", ao se experimentar os estilos das estrelas e formar grupos de dança. As garotas assistem juntas aos vídeos de dança do grupo e os imitam, muitas vezes criando seus próprios passos no processo. Mas, apesar de sua determinação em dançar, vestir-se e comportar-se como seus ídolos, muitas fãs me asseguraram de que não tinham a intenção de apenas "macaquear" o grupo, e sim buscar seu próprio estilo pessoal. Nesse sentido, esse tipo específico de cultura popular pode ser considerado uma cultura mimética. Conforme os antropólogos culturais Gunter Gebauer e Christoph Wulf, ${ }^{10}$ atos miméticos são atitudes e ações sociais independentes, mas que ao mesmo tempo se referem de certa forma a outras ações. A mimese é sempre mais do que uma simples reprodução passiva de modelos existentes; 
1 Para uma análise da dança como prática utilizada por meninas para negociar restrições sociais quanto à apresentação do corpo feminino, ver McROBBIE, 1984 e 1994. ela tem seu potencial criativo. O caráter ritualizado e mimético de certas práticas típicas da cultura de fã-clube possibilita que as/os participantes adotem uma postura cautelosa e lúdica à condição de fãs. A posição do sujeito como fã está sempre associada a outras posições de sujeito, às vezes substituindo-as. Cada uma das Spice Girls é percebida por suas fãs como uma pessoa diferente, o que faz com que a imitação das componentes do grupo envolva modos diferentes de se apresentar, conforme as qualidades que queiram evidenciar: engraçadinha, confiante ou sexy. A abordagem mimética às Spice Girls obviamente Ihes permite negociar as expectativas sociais sobre o modo como devem se movimentar e exibir seus corpos. Desse modo podem tentar se posicionar entre os extremos de não estar suficientemente 'na moda' ou seguir a moda sem questionar, entre ser comum demais ou ser sexy, entre vestirse mal ou exibir-se, e assim por diante. ${ }^{11}$

Mas os grupos de dança também servem para lidar com necessidades que vão além de simples questões de estilo. Pode-se observar isso na entrevista com Julia, de 15 anos. Julia, que se tornou fã das Spice Girls aos 13 anos, diz que costumava se considerar tímida e incapaz de lutar por seus próprios interesses. Assim, ficou muito impressionada com a assertividade que o grupo feminino Ihe transmitia. Tornou-se efetivamente uma fã ao ser convidada por amigas para participar de um grupo de dança. No início, o papel de Victoria ("spice chique") era o único disponível mas, mais tarde, ela pôde alcançar a posição de Mel B ("spice selvagem"), a quem ela admirava por ser aquela que dava o tom ao grupo.

Indagada sobre os critérios para distribuição dos papéis no grupo de dança, Julia explica:

Bem, a gente já se identificava com elas desde o início e então, aos poucos, ia entrando no papel. Nós ficávamos cada vez mais parecidas com elas. E embora Beate, que representava Emma, fosse sempre a pequeninha tímida no palco, ela era na verdade a mais confiante de todas nós. Era ela quem sempre me defendia, mas no palco era o contrário. De certa forma, nós trocávamos de papéis no palco. Então era eu quem dizia, bem, era eu que defendia todas, enquanto que fora era ela, mesmo que representasse a mais tímida.

Em termos de mimese cênica, Julia podia personificar ludicamente seu ideal de pessoa confiante e, dessa forma, provar a si mesma que era capaz de sê-lo. A troca de papéis levada a efeito entre ela e sua amiga Beate no palco permitia que elas vivenciassem uma posição completamente diferente entre seus pares, sem o perigo de conflitos ou sentimentos competitivos. Ao associar timidez 
com ser "pequeninha" e não saber se defender, Julia caracteriza seu próprio 'papel original' como uma criança dependente. Encampando o papel da confiante Mel B, ela pode experimentar a identidade de uma jovem independente que já sabe se defender. Da mesma forma, sua amiga pode se permitir, durante a mimese da dança, uma incursão na esfera de uma infância protegida. Nesse sentido, a mimese das Spice Girls pode ser descrita como uma forma de negociar a passagem da infância à juventude.

Um segundo aspecto importante da cultura de fãclube, conforme experenciada por Julia, foi a negociação de seu relacionamento com rapazes. Ela havia sido moleque enquanto criança, e mais tarde apaixonou-se por um dos membros do grupo masculino Caught in the Act, o que foi uma experiência decepcionante. As Spice Girls ilustraram para ela a atitude de que "precisamos de rapazes como amantes, mas fora isso esqueça-os, não corra atrás deles, siga seu prórpio caminho". Essa opinião lhe pareceu plausível e também a intrigou. Agora, dois anos mais tarde, ela diz:

As Spice Girls sempre passaram a idéia de que os rapazes só são interessantes se você estiver apaixonada por eles. E era basicamente isso com os Caught in the Act. Pelo menos a gente imaginava estar apaixonada por eles. E mais tarde me dei conta de que era possível ser apenas amiga de rapazes.

Enquanto isso, após esperimentar atitudes diferentes com relação ao sexo oposto na condição de fã, Julia se distancia das posições extremas em que se colocara nas várias fases daquele período. Do ponto de vista atual, ela critica tanto a atitude das Spice Girls em relação aos rapazes quanto seus próprios sentimentos em relação ao grupo masculino Caught in the Act por reduzirem as relações entre os sexos ao nível do erotismo. Enquanto que inicialmente a emoção de relacionamentos românticos típicos do mundo da música pop motivou o interesse de Julia por pessoas famosas, ela agora se sente limitada por isso e está novamente começando a ter amigos do sexo masculino. Ela se considera uma jovem esclarecida, que deixou para trás as confusões eróticas da adolescência e adotou uma atitude descomplicada em relação ao sexo oposto.

Um sentido bem diferente é atribuído às Spice Girls por Rebecca, de 17 anos, que vive numa pequena cidade do oeste da Alemanha. Aos 15 anos, enquanto todas suas amigas preferiam grupos masculinos, Rebecca era fã das Spice Girls. Como razão para isso ela aponta seu interesse pela noção de poder jovem feminino. Sua observação favorita sobre as Spice Girls era: "Uma Spice Girl pode até 
* Nota da tradutora: o termo "queer" pode significar tanto "estranhas" quanto "homossexuais". ser louca, desde que haja um método por detrás de sua loucura". O modo como Rebecca negocia o conceito de loucura é um aspecto central da entrevista. Ela se queixa das "pessoas muito normais" de sua cidade que não têm nenhuma graça. Numa atitude mimética com relação às Spice Girls, ela colocou piercings e descreve de forma engraçada outras maneiras encontradas por ela e por sua melhor amiga para fazer com que sua avó exclamasse: "O que é que os vizinhos vão pensar?" A assertividade de Rebecca ao desconsiderar normas sociais fica clara quando lhe pergunto por que a maioria das meninas preferem grupos masculinos e ela responde: "Não consigo entendê-las, elas são um tanto 'queer'". Ao se referir ao contexto heterossexual dos fã-clubes de grupos masculinos através de um termo que normalmente é usado para discriminar homossexuais, Rebecca, lúdica e ironicamente, inverte as convenções de seu ambiente. Assim como para Julia, sua condição de fã está fortemente relacionada às expectativas da sociedade de que, durante a fase da juventude, as primeiras experiências ocorram no campo da heterossexualidade. Mas enquanto Julia fez uso da cultura de fá-clube para negociar seus novos relacionamentos com rapazes, o interesse de Rebecca pelo grupo feminino ajudou-a a dissociar-se dessa expectativa. Mas ela também associa o comportamento não-convencional ao perigo de ser vista como anormal. Rebecca adora desenhar e descreve um de seus quadros dizendo: "Parece completamente psicopático. A gente poderia pensar que foi pintado por alguém completamente fora de si". Apesar disso, ela quer freqüentar uma escola de arte: "Não há perspectivas na arte. A gente quer fazer, mas não sabe aonde isso vai levar. Mas as Spice Girls me ensinaram a dizer: 'Vou fazer isto e isto vai significar alguma coisa"'.

Voltando à minha indagação sobre se as Spice Girls, como fenômeno pop feminista, podem ser consideradas uma fonte de empoderamento para as jovens, seria possível identificar Rebecca - em oposição a Julia - como o protótipo de uma fã empoderada. Graças ao grupo feminino, ela consegue não se preocupar com os rapazes, ter um comportamento não-conformista e provocativo, e lutar por uma carreira artística. Mas essa perspectiva vem acompanhada por alguns problemas. Por exemplo, concede às Spice Girls mais poder sobre as vidas de suas fãs do que elas realmente têm. As várias interpretações e aplicações dadas pelas jovens ao conceito de "poder jovem feminino" e outras mensagens incorporadas pelo grupo deixam claro que as Spice Girls não desencadeiam formas específicas de comportamento em suas fãs. São as fãs que sabem usar a imagem que o grupo feminino tem na mídia como ferramentas para serem convenientemente 
12 Quanto a isso, concordo com John FISKE, 1992, que considera fã-clube como um grupo especialmente exigente e selecionado de consumidoras/es.

${ }^{13}$ STACEY, 1994, p. 234 et seq.

14 Várias/os autoras/es indicaram uma crescente pressão sobre as/ os jovens no sentido de criar uma identidade autêntica diferenciada. Ver, por exemplo, Hillevi GANETZ, 1995.

${ }^{15}$ ABERCROMBIE E LONGHURST, 1998.

\footnotetext{
${ }^{16}$ Esse argumento é muito bem examinado no estudo de Dafna Lemish sobre o público. Ver LEMISH, 1998.
}

utilizadas na busca de seus objetivos individuais. ${ }^{12}$ Ainda, uma distinção entre os comportamentos rebelde e conformista das fãs é problemática na medida em que pode resultar no apagamento dos muitos aspectos da cultura de fã-clube feminina que não são explicitamente rebeldes, mas que são mesmo assim muito criativos. Por exemplo, o uso da imitação da dança para testar várias maneiras de se apresentar aos outros não é nem um caso simples de conformismo, nem necessariamente uma liberação. Mas demonstra como fãs inteligentes das Spice Girls podem utilizar sua cultura para aprender a lidar com as necessidades da adolescência.

Em seu estudo sobre o cinema de Hollywood e as espectadoras mulheres, Jackie Stacey ${ }^{13}$ observa que desde a expansão do consumismo na década de 1950 a relação entre auto-imagem e ideais de estrelato tem se tornado cada vez mais interativa. O ato do consumo nos dá a oportunidade de nos tornarmos semelhantes às grandes estrelas através da auto-transformação mimética. De acordo com esse argumento, as Spice Girls não são ídolos distantes para suas platéias, mas uma verdadeira mercadoria, que pode ser integrada em suas táticas de consumo. As garotas que entrevistei enfatizaram que não queriam se transformar nas cantoras, e sim encontrar seus próprios estilos. Elas não parecem se sentir limitadas pelos ditames da moda que 0 grupo representa. A idéia de que temos que ter vontade própria e escolher entre uma gama diversificada de modas e estilos tornou-se ela mesma uma norma, norma essa que pode ser negociada no interior de uma cultura mimética como a dos fã-clubes. ${ }^{14}$

Nesse sentido, concordo com Abercrombie e Longhurst, ${ }^{15}$ que destacam que certas mudanças no panorama da mídia não podem mais ser analisadas dentro de um paradigma baseado na alternativa entre resistência ou incorporação à ideologia dominante. Os autores defendem a tese de que fenômenos como as complexas atividades de fãs e espectadoras/es entusiastas em especial devem ser interpretadas dentro de paradigmas que focalizem questões de identidade e de identificação. Em meu estudo, essas idéias parecem ter sido confirmadas. Acredito que as Spice Girls podem servir para o seu jovem público como um caminho para a liberação de uma normatividade de gênero limitadora. A imagem do grupo feminino na mídia também pode ter um efeito limitador, uma vez que mantém a ideologia da importância da aparência para a identidade feminina. ${ }^{16}$ Mas, acima de tudo, uma interpretação dos relatos das fãs das Spice Girls nos permite verificar quais expectativas normativas são importantes para as adolescentes e como elas aprendem 
17 Tal conceituação de empoderamento corresponde à definição de Lawrence Grossberg. GROSSBERG, 1992, p. 64, afirma que o empoderamento não "garante qualquer forma de resistência às ou fuga das estruturas de poder existentes, embora seja uma condição para a possibilidade de resistência. [...] Empoderamento se refere à geração de energia e paixão, à construção da possibilidade". a lidar com tais expectativas. A cultura de fã-clube proporciona a elas a oportunidade de abordar ludicamente questões de auto-representação, confiança e heterossexualidade, que podem, embora não necessariamente tenham que, ser utilizadas para resistência. Nesse sentido, as Spice Girls podem ser vistas como uma fonte de empoderamento para suas fãs. Elas estão bastante associadas à posição de sujeito de uma adolescente forte, confiante e bem-sucedida, e oferecem um atraente ponto de referência para suas atividades culturais. $O$ tremendo sucesso do grupo feminino explica a longa ausência de símbolos como esses nas vidas de mulheres jovens e legitima as demandas feministas por novas representações da feminidade na mídia.

Mas não é apenas a partir dessa perspectiva que argumento que as Spice Girls devem ser levadas a sério nas discussões de feministas acadêmicas. As táticas criativas das fãs do grupo nos ensinam as muitas variações possíveis do empoderamento para garotas. ${ }^{17} \mathrm{E}$ um reconhecimento do potencial político do empoderamento transmitido pela cultura popular pode ser pré-condição para uma estratégia feminista que busque aumentar as possibilidades das jovens de lidar com as exigências da sociedade moderna. As metas do feminismo de aumentar o raio de ação das jovens (e das mulheres) não podem ser alcançadas apenas através de palavras. Pelo contrário, para mim parece importante aprender a entender as maneiras comuns, lúdicas e corporificadas, através das quais essas jovens lidam com os scripts sociais da identidade. Esta seria uma pré-condição necessária para encorajá-las a perseguir aspectos de sua própria identidade que não se adaptam a tais normas.

\section{Referências bibliográficas}

ABERCROMBIE, Nicholas, and LONGHURST, Brian. Audiences: A Sociological Theory of Performance and Imagination. London: Sage, 1998.

ANG, len. "Culture and Communications: Towards an Ethnographic Critique of Media Consumption in the Transnational Media System." European Journal of Communication, n. 5,1990 , p. 239-260.

. "Ethnography and Radical Contextualism in Audience Studies". In: ANG, len. Living Room Wars: Rethinking Media Audiences for a Postmodern World. London: Routledge, 1996. p. 66-81.

BOHNSACK, Ralf, LOOS, Peter, and PRZYBORSKI, Aglaja. "'Male Honour': Towards an Understanding of the Construction of Gender Relations Among Youths of Turkish Origin." In: KOTTHOFF, Helga, and BARON, Bettina. (eds.). Gender in Interaction: Perspectives on Femininity and Masculinity in Ethnography and Discourse. Amsterdam: Benjamins Publishing Co., 2001. p.175-207. 
DIBBEN, Nicola. "Representations of Femininity in Popular Music." Popular Music, n. 18, 1999, p. 331-355.

FISKE, John. "The Cultural Economy of Fandom." In: LEWIS, Lisa A. (ed.) Adoring Audience: Fan Culture and Popular Media. London: Routledge, 1992. p. 30-49.

GANETZ, Hillevi. "The Shop, the Home and Feminity as a Masquerade". In: FORNÄS, Johan, and BOLIN, Göran (eds.). Youth Culture in Late Modernity. London: Sage, 1995. p. $72-$ 99.

GARBER, Marjorie. Vested Interests: Cross-Dressing and Cultural Anxiety. London: Routledge, 1993.

GEBAUER, Gunter; WULF, Christoph. Spiel Ritual Geste. Mimetisches Handeln in der Sozialen Welt. Reinbek, Hamburg, 1998.

GROSSBERG, Lawrence. "Is There a Fan in the House?: The Affective Sensibility of Fandom." In: LEWIS, Lisa A. (ed.) Adoring Audience: Fan Culture and Popular Media. London: Routledge, 1992. p. 50-65.

. "MTV: Swinging on the (Postmodern) Star" In: MUNNS, Jessica, and RAJAN, Gita. (eds.). A Cultural Studies Reader: History, Theory, Practice. London: Longman Group, 1995. p. 369-376.

LEMISH, Dafna. "'Spice Girls' Talk: a Case Study in the Development of Gendered Identity." In: INNESS, Sherrie A. (ed.). Millennium Girls: Today's Girls Around the World. New York: Rowman \& Littelfield Publishers, 1998. p. 145-167.

"Spice World: Constructing Femininity The Popular Way". Popular Music and Society, v. 26, n. 1, 2003, p. 17-29.

McROBBIE, Angela. "Dance and Social Fantasy." In: MCROBBIE, Angela, and NAVA, Mica (eds.). Gender and Generation. London: Macmillan, 1984. p. 130-161.

. "Shut up and Dance: Youth Culture and Changing Modes of Femininity." In: McROBBIE, Angela. Postmodernism and Popular Culture. London: Routledge, 1994. p. 155-176.

. "Muskelpakete und Schwänze. Die Bedeutung von Girlie-Kultur." In: BALDAUF, Anette; WEINGARTNER, Katharina. (eds.). Lips Tits Hits Power? Popkultur und Feminismus. Bozen, Wien, 1998. p. 274-284.

MANNHEIM, Karl. Essays on The Sociology of Knowledge. London: Routledge \& Kegan Paul, 1952.

RADWAY, Janice. "Reception Study: Ethnography and the Problems of Dispersed Audiences and Nomadic Subjects." Cultural Studies, v. 2, n. 3, 1988, p. 359-376.

ROLLING STONE. Issue 156, March 20, 1997.

STACEY, Jackie. Star Gazing: Hollywood Cinema and Female Spectatorship. London: Routledge, 1994.

WALD, Gayle. "Just a Girl?: Rock Music, Feminism, and the Cultural Construction of Female Youth." Signs: Journal of Women in Culture and Society, v. 23, n. 3, 1998, p. 585-610.

[Recebido em dezembro de 2003 e aceito para publicação em julho de 2004] 


\section{Negotiations of Pop Feminism in Girl Culture: An Empirical Study about Girlgroup-fans}

Abstract: The Spice Girls as one of the most successful bands of the nineteen-nineties have become particularly famous for their proclamation of 'girl power'. With reference to an interviewbased study with fans and ex-fans of the girl group the article discusses to what extent 'pop feminist' phenomena like the Spice Girls can be considered a source of empowerment for young women and girls. The 'documentary method' is introduced as a method which allows the analysis of media reception as part of a popular culture. A mimetic approach towards the Spice Girls within this popular culture allows their fans to experiment in finding their own position between the contradictory demands society makes on them as adolescents. It will be shown that their complicated negotiations refer to an empowerment which cannot be adequately grasped within categories of resistance and incorporation of ideology.

Key words: girl culture, feminism, mimesis, methodology in audience studies.

Tradução: Susana Bornéo Funck Revisão da tradução: Simone Pereira Schmidt 